San Antonio Review • WordPress Imports (Pending Organization) - lan: You can use this.

\title{
Cannabis Can Save the South
}

Published on: Oct 04, 2017

License:Creative Commons Attribution 4.0 International License(CC-BY 4.0). 
by William O. Pate II

The South is suffering. The South has long been suffering.

Largely rural, states like Alabama and Mississippi have lost out on the rise of the information technology sector. High tech companies don't tend

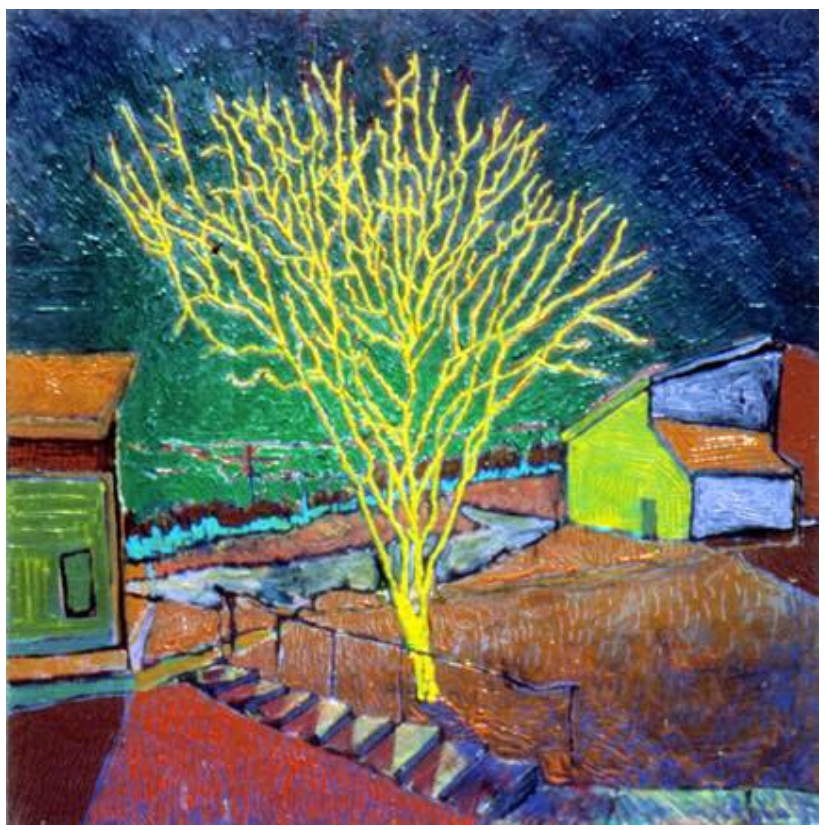
to flock to even the largest cities

- Birmingham, Mobile and the state capital of Montgomery - in the state of Alabama.

Alabama's March 2017 unemployment rate was over a percentage point higher than the national rate. To pursue successful, financially prosperous careers, people must leave the state. With an underfunded education system, most students will never make it out.

Wouldn't it be wonderful if there was an industry that could bolster the state's industry, tax revenues and job opportunities?

Cannabis cultivation and the biomedical research growing up around it could serve as a slingshot into the future for Southern states.

Alabama, Mississippi and other Southern states are already geared toward large-scale agricultural production. They have wonderful 
climates for marijuana growth. It would take very little for those state legislatures to pull their heads out of their right-wing asses and legalize cannabis. A slight amount of funding to state universities to spur research into the medicinal benefits of the drug could result in new biomedical businesses and an influx of highly educated researchers. The University of Mississippi is already the only college with federal blessing to grow marijuana.

Because marijuana can't cross state lines due to its federal classification, states are able to protect and help their cannabis industries grow before nationwide legalization propels them into the national and international markets. Southern states are losing a golden - green? - opportunity to light up the joint with progressive public policy focused on employment, small business and tax revenue growth.

Colorado and Washington are bringing in billions of dollars in tax revenue from the regulated sale of cannabis products. Just think of what those dollars could do for the underfunded public schools of Southern states. It would be a windfall beyond the dreams of legalized gambling proponents.

Further, marijuana has been shown to be an effective replacement for many opiates - possibly helping end the addiction epidemic in those states. (Marijuana is not physically addictive.)

There are just too many positive aspects to the cultivation of cannabis in these states for legislators to continue ignoring them. Misguided 
policy is misguided policy. It's time for Southern state legislators to look to the future; one of the few industries in which the ground floor is currently accessible should not be discarded just because it involves pot. 